Artículo de reflexión

Cómo citar: Guzmán, N., y Di Giorgi, F. (2019). Cuestionando los marcos normativos. La apuesta crítica desde la materialidad corporal en Judith Butler, Polisemia, 15(28), 24-45. http://doi.org/10.26620/uniminuto. polisemia.15.28.2019.24-45.

ISSN: 1900-4648

elSSN: $2590-8189$

Editorial: Corporación Universitaria Minuto de Dios - UNIMINUTO

Recibido: 5 julio 2019

Aceptado: 25 agosto 2019

Publicado: 25 octubre 2019
Nataly Guzmán Useche y Luz Helena Di Giorgi Fonseca

\section{Cuestionando los marcos} normativos. La apuesta crítica desde la materialidad corporal en Judith Butler

\author{
Questioning the normatives \\ frameworks. Judith Butler's critical bet \\ to bodily materiality
}

\section{Questionando os quadros normativos. A aposta crítica desde a materialidade corporal em Judith Butler}

\section{Resumen}

Este artículo presenta la importancia de las reflexiones teóricas de la filósofa Judith Butler acerca del género y la diferencia sexual en la producción de las identidades y los procesos de subjetivación. El texto analiza las consecuencias prácticas que tiene el ejercicio deconstructivo y genealógico en la reflexión de la materialidad de los cuerpos sobre las categorías mencionadas. Finalmente se demuestra que los marcos normativos, reproducen y mantienen, formas de exclusión que se alojan en el campo jurídico.

Palabras clave: género, identidad, Judith Butler, marcos normativos, performatividad. 


\begin{abstract}
This dissertation exposes the importance of the theoretical reflections of the philosopher Judith Butler on notions about gender and sexual differences in the production of identities and the processes of subjectivation. The article focuses on presenting the practical consequences that the deconstructive and genealogical exercise has on the reflection of the materiality of the bodies, regarding the categories mentioned, demonstrating evidence that the normative frameworks reproduce and maintain forms of exclusion that exist in the legal field.
\end{abstract}

Keywords: gender, identity, Judith Butler, normative frameworks, performativity.

\title{
Resumo
}

O presente artigo expõe a importância da reflexão teórica da filósofa Judith Butler sobre noçóes de gênero e diferenças de sexualidade nos processos de identidade e criação de subjetividades. $\mathrm{O}$ artigo foca na apresentação prática de consequências da desconstrução e exercícios genealógicos tem refletido na materialidade dos corpos considerando as categorias mencionadas. Finalmente, se comprova, que os marcos normativos, reproduzem e ajudam a manter, formas de exclusão que caracterizam o corpo jurídico.

Palavras-chave: gênero, identidade, Judith Butler, marcos normativos, performatividade. 


\section{Introducción}

La filósofa norteamericana Judith Butler ofrece una serie de indagaciones y apuestas teóricas que enriquecen la discusión alrededor de la noción de género en los discursos del poder. Para ella es fundamental considerar las consecuencias que tienen, en la producción de lo abyecto ${ }^{1}$, los discursos institucionales que organizan la vida social, tal como lo hace el derecho. Gran parte de su obra se concentra en hacer un ejercicio crítico a la fundamentación filosófica de las categorías que establecen qué vidas han de ser reconocidas y cuáles no. Sin embargo, hay que advertir que los análisis teóricos de Butler sobre la performatividad del género van más allá de una crítica teórica, en tanto que, se preocupa por hacer evidentes las formas de opresión que se producen con las categorías identitarias. Un aspecto que resulta interesante de su propuesta tiene que ver con la necesidad de pensar la agencia de los sujetos, pese a que éstos están limitados para rechazar las categorías que los producen y constituyen como tal, pues rebelarse contra el sistema de sujeción implica la anulación de sí; de allí que, los sujetos estén atados a tramitar su existencia con tales categorías. En este sentido, el objetivo del artículo es poner en evidencia las reflexiones y discusiones que establece Judith Butler con las interpretaciones del género y la diferencia sexual que provienen del feminismo constructivista, el psicoanálisis, la tradición filosófica y el campo lingüístico, con el fin de poner en cuestión las formas institucionales que contribuyen a la vulnerabilidad de los sujetos, en la medida que producen y reproducen formas de materialización corporal que son excluyentes.

Es importante considerar que las influencias del ejercicio crítico de Butler están determinadas por las reflexiones elaboradas por Raymond Williams y Theodor Adorno, pero especialmente por Michel Foucault, debido a que las preocupaciones de estos autores se encuentran relacionadas con el topos ético-político relativo a la identidad y a los procesos de subjetivación. Para Butler, el ejercicio crítico no consiste en la creación de un juicio de valor sobre las certezas epistemológicas que configuran un tipo de ordenamiento social, sino que radica en la formulación de una serie de preguntas que tienen que ver con la relación existente entre saber y poder. Puesto que, desde allí aparecen los límites que envuelven las certezas epistemológicas en la configuración del ordenamiento social y la generación de zonas de exclusión, al respecto afirma Butler que: “[...] es a través de una rasgadura en el tejido de nuestra red epistemológica que la práctica de la crítica surge, con la conciencia de que ya ningún discurso es adecuado o de que nuestros discursos reinantes han producido un impás" (Butler, 2008, p. 147).

Con el fin de reconstruir estas discusiones, el presente artículo se divide en cuatro partes: la primera, reconstruye la crítica de Butler a las posturas feministas constructivistas, especialmente, la crítica a las categorías de

1 En Cuerpos que importan, Butler (2002) define lo abyecto como: "(...) aquellas zonas "inviables", "inhabitables" de la vida social que, sin embargo, están densamente pobladas por quienes no gozan de la jerarquía de los sujetos, pero cuya condición de vivir bajo el sino delo "invivible" es necesaria para circunscribir la esfera de los sujetos" (p.19-20). 
sexo y género tal y como fueron pensadas por dicha tradición; en segundo lugar, expone el proceso de materialización de los cuerpos desde un camino genealógico, demostrando las relaciones del poder discursivo en la formación de materialidades corporales; la tercera parte aborda la discusión que establece la autora con el psicoanálisis y sus estructuras falogocentricas y heteronormadas que producen exclusión; y finalmente, considera los aportes de dicha interpretación en los marcos normativos para el contexto jurídico.

\title{
¿Constructivismos contestatarios? un debate entre el idealismo y la materialidad
}

\author{
¿Por qué lo construido se entiende \\ como artificial y prescindible?
}

(Butler, 2002, p.13)

Una de las apuestas centrales de la obra de Butler consiste en cuestionar las posturas feministas ${ }^{2}$ que apuntan a una perspectiva constructivista y culturalista del género ${ }^{3}$, en las que se señala lo problemático de reducir la cuestión de género a una construcción social, dejando al terreno de lo natural, la diferencia sexual. Reconsiderar el lugar del género y el sexo, en relación con la materialidad de los cuerpos, hace evidente sus limitaciones teóricas y resalta el papel de estas dos categorías para delimitar la significación de los cuerpos en el entramado de las relaciones sociales. Por esta razón, la teoría de la performatividad butleriana, intenta descubrir los límites de la perspectiva constructivista.

Aceptando que todo constructivismo se solventa sobre la tesis de un ejercicio de creación, existen al menos dos perspectivas que desarrollan las posibilidades de esta tradición. Por una parte, el constructivismo voluntarista selectivo, que asume una realidad previa, por ejemplo, una

2 Puntualmente, se refiere a la distinción de la historiografía feminista entre el feminismo igualitario y el feminismo de la diferencia, que tendrá implicaciones en la noción del género y la naturalización de la diferencia sexual.

3 Al respecto, se amplía la discusión en Sabsay, L. (2012). De los sujetos performativos, psicoanálisis y visiones constructivistas. En: P. Soley-Beltran y L. Sabsay (eds), Judith Butler en disputa. Lecturas sobre la performatividad (pp. 135-168). Madrid: Editorial Egales. También en: Sabsay, L. (2007) Los dilemas del antiesencialismo en la teoría feminista contemporánea: una reflexión en torno a Judith Butler. Almería: Instituto de Estudios Almerienses. Por su parte, Joan Wallach Scott propone un marco interpretativo en el cual el género se entiende como un sistema completo de relaciones que pueden incluir el sexo, pero que no están directamente determinadas por él. De allí que los estudios del género se hayan plasmado en tres momentos diferentes: el puramente feminista que intenta explicar el lugar y las funciones del patriarcado; el segundo, que se apoya en las teorías marxistas y de clase sobre la objetivación sexual como diferencia física en las relaciones de dominación y; el tercero, desarrollado desde la tradición posestructuralista, puntualmente desde el psicoanálisis lacaniano, para explicar la fundamentación del yo y la identidad (Scott, 1996). 
naturaleza dada que debe ser coherentemente representada a través del lenguaje. Por otra parte, el constructivismo esencialista determinista, el cual rechaza la existencia de un objeto previo a significar, asegurando que todo es producido por el lenguaje, como recurso supremo de lo inteligible; pues si bien asume que la formación del mundo es solamente un efecto lingüístico, este hecho presupondría que la materialidad opera en el mundo como un recurso pre-teórico, fabricado para hacer formulaciones lingüísticas.

Estas dos apuestas juegan sus posiciones al interior de un constructivismo lingüístico, que se moldea y reformula entre la idea del voluntarismo selectivo y del determinismo esencialista (constructivismo lingüístico radical). En ambos casos, se vaticina una circularidad que lleva a suponer el poder efectivo del sexo y su lugar indiscutiblemente fijo, pero también suponen una operatividad de la naturaleza y un lugar de lo artificial, cruciales en la crítica butleriana.

Desde la perspectiva del constructivismo voluntarista selectivo, lo social actúa sobre lo natural imponiéndole sus parámetros y significaciones. El espacio que ocupa, entonces, lo natural resulta de una eventualidad, de una instancia de la aparición sin nombre, de un momento que espera a ser significado. Esto, trasladado al campo de la diferencia y/o relación del sexo con el género, implica que el sexo queda desarmado, perdiendo la posibilidad de significación una vez que el género como principal recurso simbólico lo ha asumido. Que el sexo sea asumido por el género, que esa página en blanco carente de vida se desplace ante la fuerza del género, implica su desustanciación (Butler, 2002). En este sentido, al estar implicada la formación discursiva de un sexo asumido desde la línea de la construcción social, de un nombrar, se cae en la creencia del poder del constructivismo lingüístico, el cual asume que todo ha sido "generado o determinado", y en ese sentido, los cuerpos (las materialidades) son el resultado exterior de un discurso. Esto implica que, la labor activa de la construcción quede cuestionada, pues si la construcción fue el resultado de una acción creadora, quién o quiénes como sujetos previos, se encargaron de ese acto del nombrar. Y ahondando la dificultad, si la acción de nombrar, como requisito de la construcción, supone un agente previo, cómo ocupó el lugar privilegiado de demarcar y fundar.

En una versión más enérgica, el constructivismo determinista esencial o radicalismo lingüístico, se esfuerza por negar cualquier existencia previa y desligada de las formas discursivas. El sexo, por lo tanto, no se transustancia en un discurso cultural que se representa a través del género, sino que hace parte del juego prediscursivo que da coherencia al sistema de validez implícito. Para esta perspectiva, no hay una consideración del cuerpo dado o de una materia precedente. Por tanto, al poner en inminente negación el acceso al sexo, este constructivismo da por supuesto que se ha instaurado en un espacio eterno, como un dios, que no solo causa, sino que compone todo lo que es su objeto. De allí que, el constructivismo radical necesite de la ficción o de la fantasía del sexo, instalada en el lugar prelingüístico.

Esto conlleva a considerar que toda construcción resultante de este monismo lingüístico deja exento el lugar vívido de los cuerpos, o bien 
bajo un determinismo de sentido, o bien bajo un voluntarismo racional (Butler, 2002) que operan apelando a la ficción de un yo o un nosotros previo. En este sentido, el sujeto presupuesto como agente constructivo de su orden de cosas, invoca una versión del humanismo idealizado, que excluye las orquestaciones propias de la matriz de generización, aquella que sujeta y subjetiva a través del marco relacional de la diferenciación sexual, y la cual, en la asunción de Butler, resuelve el límite interpretativo del constructivismo, porque le permite un lugar a la capacidad reguladora frente a la materialización de los cuerpos.

La crítica formulada por Butler deja en claro que tanto el idealismo como el materialismo feminista se establecen sobre las premisas del sistema heteronormativo que esas mismas apuestas filosóficas critican. El núcleo central de la cuestión se funda en la separación planteada por Simone de Beauvoir ${ }^{4}$ entre el sexo naturalizado y el género construido, postulando que el sexo (la diferencia sexual) es también discursivo. La conceptualización del género en la interpretación de Butler, que se rastrea desde su texto legendario El género en disputa, evidencia la caracterización de éste como social y culturalmente construido y ubica la diferencia sexual en un plano de la naturalización que lo blinda de su posible crítica (Sabsay, 2010).

El paradigma que deja intacta la diferenciación del género y el sexo, desde la postura butleriana, respetaría los lugares del código binario e incluso contribuiría a fortalecer las funciones del poder de nombrar en los dos sentidos. La norma heterocentrada trae implícita otra aporía en lo relativo al género socioculturalmente comprendido, según la cual, se debería reconocer la existencia de un sujeto previo al género y al sexo, un sujeto deliberativo y voluntarista que se reduce a un humanismo monista e indistinguible: un cuerpo limpio, sin signos, clínicamente establecido en el centro de la elección o bien un cuerpo inteligentemente determinado por una fuerza, idealista y extraña a él, que le vincularía con un género y un sexo, y de esa manera lo identifica para existir.

Estas críticas resaltan las formas en las que el poder constituye al sujeto a través de la relación binaria hombre-mujer, tal como lo menciona J. Scott en su texto: El género una categoría útil para el análisis histórico (1996). La reflexión butleriana da un paso adelante desde una crítica ontológica, extendiendo su ataque desde el discurso de género como referencia cultural heteronormativa, hasta la formación del sexo en el mismo sentido (Butler, 2007). Si bien Scott puso en cuestión la falacia de los órdenes de la sexualidad y el género, por ser considerados naturales o innatos, Butler desmantela el hecho de usar la diferencia corporal para fomentar las representaciones sobre los cuerpos, atribuyéndoles características distintivas. En la fabricación de esa representación, el discurso jurídico forma la noción de sujeto a través de prácticas de exclusión, y sobre él se desarrolla, definiendo a hombres y mujeres con representaciones universales.

4 La categoría de Beauvoir se concentra en demostrar el carácter histórico, social y cultural de la formulación del género a partir de la diferencia biológica, descubriendo a este como concepto para la proyección del pensamiento feminista (Beauvoir, 2005). 
Las premisas generales de la crítica al constructivismo, establecido por Butler, cuestionan principalmente la idea de sujeto atado a la diferencia sexual, por medio de un yo y un nosotros anterior a las actuaciones ejercidas por la capacidad regulatoria iterada. En este sentido, cualquier apreciación del constructivismo que implique agentes activos previos a la formación, o un sujeto racional que elige su propia ruta de identificación sexual, es errada en cuanto no da lugar al papel de la matriz del poder, la cual opera desde la iteración, configurando ritualmente la performatividad.

Este proceso de crítica a la diferencia entre sexo y género le permite a Butler inaugurar un análisis genealógico de la materialización corporal, fomentando una línea de investigación sobre los presupuestos filosóficos y psicoanalíticos que han servido como justificación para comprender tanto los procesos de subjetivación, como las estructuras de poder que normalizan la aparición de los cuerpos a partir de una identidad estable. En este análisis, Butler muestra que la escenografía y la topología de la materia, se construyen tanto en la formación material como desde la aproximación psíquica. Esto implica que la materialidad de los cuerpos responde a una doble condición, que se condensa en la tensión entre el poder simbólico y el lugar de lo imaginario, que determina los juegos entre las identidades fijas, coherentes, y las identidades inestables.

\title{
Matriz de poder: una reflexión genealógica
}

\author{
Aqui correspondería escribir el término "ser" entre comillas, \\ porque el peso ontológico nunca se supone, \\ sino que siempre se otorga.
}

(Butler, 2002, p. 639)

Esta sección aborda el análisis butleriano de los procesos de materialización corporal, con el propósito de mostrar por qué la noción de materia es importante para la reflexión de la performatividad. En términos generales, el proceso de materialización es un camino que revela cómo, a partir de una serie de discursos que provienen de la filosofía occidental, los cuerpos se hacen inteligibles y adquieren una identidad. Es importante advertir que esta perspectiva configura la crítica de Butler a las posturas constructivistas y estructuralistas ${ }^{5}$ ya enunciadas. Las preguntas que formula la autora alrededor de esta crítica son las siguientes: ¿Cuál es la idea fundadora, clásica, de la inteligibilidad corporal?, ¿qué se circunscribe en la esfera de lo que es materializable y cuáles son las modalidades de la materialización?

5 En El género en disputa, Butler (2007) hace una reflexión y crítica al estructuralismo de tradición levi-straussiana la cual considera que existe una estructura universal que da cuenta de la regulación de las relaciones humanas, más precisamente de los sistemas de parentesco. 
Butler, al igual que Lucy Irigaray, considera que es importante ir a la historia de la filosofía para rastrear la constitución discursiva del sexo, en tanto que, misteriosamente se le ha concebido como un ente artificial, una especie de superficie naturalizada, que no merece reflexión. Este aspecto lo describe Irigaray en la entrevista "El poder del discurso", en la que pone en cuestión la postura psicoanalítica que hace Sigmund Freud alrededor del sexo; allí asegura que:

Freud describe un estado de hecho. No inventa una sexualidad femenina, ni masculina, por lo demás. Elabora un informe, como «hombre de ciencia». El problema es que no examina las determinaciones históricas de los datos que trata. Y, por ejemplo, que acepta como norma la sexualidad femenina tal como ésta se le presenta. (Irigaray, 2009, p. 52)

De la misma forma que Irigaray, Butler (2002) considera que el sexo no es algo dado, ni un ente estático o artificial, sino que es una norma por la cual un sujeto es inteligible a nivel cultural. Por ello, una de sus principales preocupaciones es mostrar cómo un sujeto asume la norma, pero especialmente, cómo esa asunción se da apasionadamente a través de un proceso de identificación en el que emerge el Yo. Para llevar a cabo esta tarea, Butler recurre al proceso de materialización debido a que no considera que el sujeto asuma la norma obedientemente, sino que, es a través de las formas de constitución de aquellas, que se produce, moldea y hace viable la vida misma; al respecto afirma que: "La 'materialidad' sólo aparece cuando se borra, se oculta, se cubre su condición de cosa constituida contingentemente a través del discurso. La materialidad es el efecto disimulado del poder" (Butler, 2002, p. 65). En este punto, cabe advertir que la intención no es sólo mostrar la dificultad que se tiene al determinar el sitio del sexo en el discurso, como lo sugiere Irigaray, sino encontrar los límites de esa inteligibilidad a partir de las morfologías sexuadas.

En la búsqueda genealógica de la materia, Butler pretende rastrear el lugar que ha tenido el sexo en los discursos de inteligibilidad corporal, porque "[...] en cada uno de estos contextos la inestabilidad que produce el esfuerzo por fijar el sitio del cuerpo sexuado desafía los límites de la inteligibilidad discursiva" (Butler, 2002, p. 39). Esta reflexión es importante, pues a partir de allí, los cuerpos empiezan a significar y, por tanto, adquieren reconocimiento. El proceso de materialización considera los siguientes momentos: 1) muestra cómo la materia es una efecto del poder; 2) que tal efecto de poder se da a partir de un acto reiterativo de una norma reguladora; 3 ) la aparición del sexo como norma cultural; 4) la formación del yo, en el momento en el que se asume el sexo; 5) la asunción del sexo como una forma de identificación con los medios discursivos. La autora al darse cuenta de que el sexo se ha considerado una superficie o un ente dado, desde donde los discursos sobre el cuerpo empiezan sus indagaciones, establece que no hay una materia anterior al discurso; sin embargo, una de las preguntas que queda al aire es si en este proceso de materialización algo se escapa, es decir, ¿qué del cuerpo queda por fuera del discurso?

Considerar la asunción del sexo y el género como procesos de materialización evidencia una de las afirmaciones que ya Foucault había 
planteado en: Historia de la sexualidad I (2007), en el que se refiere al análisis del poder, a partir de la indagación de los dispositivos que producen su eficacia en la constitución de la subjetividad, que no es simplemente el acto de obediencia de un sujeto a la ley, sino el papel productivo de las leyes en la constitución del sujeto. $\mathrm{Al}$ respecto sugiere Burgos:

[...] el momento en el que la materia se considera punto de partida para posteriores elaboraciones teóricas y políticas, es, afirma Butler, la ocasión propicia para que el poder oculte sus mecanismos de producción velando el conocimiento de que aquel llamado lugar epistemológicamente fundante es resultado de complejas relaciones de poder y discurso. (2008, p. 227)

Butler afirma que analizar la localización metafísica de la materia abre la oportunidad de pensar, en primer lugar, en una posible agencia del sujeto y, en segundo lugar, en distintas configuraciones de los cuerpos. En últimas, pensar hasta qué punto la materia puede ocupar "[...] otros espacios y sirva a objetivos políticos muy diferentes" (Butler, 2002, p. 56), incluso des-localizarla, para que así los cuerpos importen de otro modo. Para la autora, la perspectiva de Foucault permite comprender cuáles son los efectos regulatorios de las relaciones de poder, pero deja por fuera de consideración lo que no se configura a través de estas relaciones,

[...] Foucault describe el proceso de materialización como investidura del discurso y el poder, se concentra en la dimensión productiva y formativa del poder. Pero nosotros debemos preguntarnos qué circunscribe la esfera de lo que es materializable y si hay modalidades de materialización, como lo sugiere Aristóteles y Althusser [...]. (Butler, 2002, p. 65)

Por esta razón, reflexiona alrededor de los conceptos de ideal regulatorio y matriz de generización. El término ideal regulatorio tiene que ver con la manera como la norma regula, pero a la vez produce, demarca, circunscribe y diferencia el cuerpo, de alguna manera, es una forma de considerar lo que la norma produce. Por su parte, la matriz de generización refiere a las condiciones de operación y formación de sujeto, específicamente a "las relaciones diferenciadoras mediante las cuales los sujetos hablantes cobran vida" (Butler, 2002, p. 25). Bajo esta perspectiva el sujeto emerge a través de las relaciones de género establecidas, lo que indica que no es un acto de regulación de una vez y para siempre, sino que opera a través de constantes ejercicios de sedimentación, de formación de espacios excluidos o abyectos.

La repetición de la ley reguladora genera la posibilidad de identificación. Este acto performativo que produce lo que nombra, identifica los cuerpos a través de las normas de la diferencia sexual, y los afianza en el acto de iteración como estrategia de emergencia del yo,

[...]el proceso de esa sedimentación o lo que podríamos llamar la materialización será una especie de apelación a las citas, la adquisición del ser mediante la cita del poder, una cita que establece una complicidad originaria con el poder en la formación del yo. (Butler, 2002, p. 38) 
El sexo y el género como ideales regulatorios muestran que la producción subjetiva está implicada en la matriz de poder y que se establecen por el repudio a identificaciones temidas. Butler formula una reflexión genealógica de la escenografía y la topografía que configura la inteligibilidad corporal en estas formas teóricas. Para el caso, muestra cómo las formas discursivas contemporáneas, que hablan acerca del proceso de materialización del cuerpo, implican aún la tensión entre forma/materia establecida por la teoría clásica occidental. En Cuerpos que importan, Butler (2002) recurre a las reflexiones hechas por Foucault e Irigary, quienes reinterpretan y ponen en cuestión las premisas fundadoras de inteligibilidad que provienen del pensamiento de Aristóteles y Platón.

Butler recurre a Foucault, en tanto considera que, en Vigilar y castigar (2009), éste reinterpreta una de las premisas fundadoras de la inteligibilidad corporal planteada por Aristóteles, a partir de las reflexiones que estableció acerca de la relación entre alma (Shema) y el cuerpo (Hyle), en el que considera al "alma" como centro de análisis a la hora de revisar el papel de las medidas punitivas de la sociedad moderna, en este caso, el alma como instrumento político. Butler asegura que, en Vigilar $y$ castigar, Foucault hace una descripción aristotélica de la materialización del cuerpo del prisionero, en la que el alma se convierte en aquel instrumento que permite afirmar y sujetar al cuerpo. Según la autora, el alma designa la realización de la materia, es decir, aquello que le otorga forma e inteligibilidad al cuerpo. De allí que, según Butler, bajo la perspectiva aristotélica exista un vínculo indisoluble entre la materialidad y la inteligibilidad, pues la materia en sí misma envuelve su condición de posibilidad y la hace comprensible a través de la Shema o forma.

En este punto, es preciso advertir que tales consideraciones han tenido un efecto importante en las construcciones de la subjetividad moderna, especialmente, en la participación de los sujetos en el cuerpo político. Tal y como lo advierte Moira Gatens en su libro Imaginary bodies (1996), en el que asegura que en el siglo XVII ${ }^{6}$ se consolida la formación de una sociedad racional que garantiza la protección de los cuerpos que la constituyen. Por ejemplo, en el contrato social hobbesiano se establece bajo la imagen de un hombre racional que tiene la capacidad de abandonar su estado de naturaleza previo para establecer su lugar en el espacio político estatal, contrario al lugar de las mujeres quienes no lograron abandonar su estado de naturaleza; al respecto afirma Gatens:

Woman in fact never makes the transition from the mythical 'state of nature' to the body politics. She becomes nature. She is necessary to the functioning of cultural life, she is the very ground which makes cultural life possible, yet she is not part of it. (1996, p. 51)

6 "The seventeenth century was witness to at least two births of interest to us here. First, the birth of the human subject who is both the subject of governance, that is, subject to an internal relation of domination, where mind or reason should dominate the body and passion, and one subject to governance. Second, the birth of the modern body politic which is represented as a product of reason, designed to govern, manage and administer the needs and desires of its subjects" (Gatens, 1996, p. 50). 
En este sentido, la autora considera que, desde la perspectiva histórica, las mujeres han ocupado la condición de un cuerpo naturalizado, fundador de la cultura, pero excluido de la sociedad civil.

En esa época, el cuerpo se identificaba como un elemento que cae bajo las determinaciones de la naturaleza, mientras que al alma o al pensamiento se le reconocía la capacidad de distanciarse de esa condición natural. En el caso de las mujeres, se creía que ellas representaban lo corporal, mientras que los hombres estaban vinculados al pensamiento y la dominación. Comprender de esta manera el cuerpo de las mujeres y los hombres hace que, cada uno, por sus características asuman un rol distinto (Di Giorgi, 2013, p.11).

Gatens (1996) advierte que estas consideraciones han tenido resonancia en posturas feministas como: las de Simone Beauvoir y Shulamith Firestone, en tanto que acogen la consideración natural del cuerpo femenino y el sexo como un hecho indiscutible de los cuerpos. En este sentido, el cuerpo ocupa un lugar fijo, aspecto que para las feministas como Irigaray es relevante, pues ella intenta analizar las distintas representaciones de lo femenino desde allí.

Butler recurre a los planteamientos hechos por Lucy Irigaray ${ }^{7}$, al mostrar cómo las oposiciones binarias emergen de la economía falogocéntrica que produce "lo femenino" a partir de la consideración de la materia como sitio de exclusión, en donde se relegó a lo femenino. La tesis de Irigaray radica en que sobre lo femenino solo se ha realizado una representación fantasmática asociada a la noción de materia, quedando, al mismo tiempo, excluida al no ser nombrada. Es preciso advertir que, la postura de Irigaray no radica en identificar lo femenino con la consideración occidental de materia que es entendida desde Platón como receptáculo o materia que genera los cuerpos-, el problema que ella evidencia es que a partir de esa identificación fundacional se ubica a lo femenino como una exclusión constitutiva.

Si bien lo femenino desde el discurso filosófico occidental, para Irigaray, toma el rol de chora platónica, entonces, solo puede ser considerada como un topos receptivo "estéril", que solo puede ser penetrado, pero nunca penetrar; por el contrario, lo masculino asume una posición ontológica superior, debido a que posee tal facultad. En esta medida, según Butler, Irigaray interpreta la cosmogonía de las formas del Timeo, a través de una fantasía fálica, en la que lo femenino se relaciona con esos significados espurios de la materia. Solo bajo una figura catacrésica ${ }^{8}$ se puede pensar lo femenino como receptáculo, al respecto afirma Butler que: "Lo femenino, para usar una catacresis, se doméstica y vuelve ininteligible dentro del falogocentrismo que se pretende autoconstituyente" (Butler, 2002, p. 72).

7 Para ampliar este punto se puede revisar el capítulo "Espéculo": Una madre de hielo, en: Irigaray, L. (2007). Espéculo de otra mujer. Madrid: Akal.

8 La catacresis es una figura retórica que consiste en designar una cosa, careciendo de nombre, usando el nombre de otra. Funciona como una sinécdoque, metonimia o metáfora. Ejemplos: "El cuello de la botella", "los brazos del sillón", "la cabeza del alfiler (Etimologías.dechile.net, s.f.). Aparece por la ausencia de nombre. Transferencia inapropiada de sentido. 
De la oposición binaria, es lo excluido lo que difícilmente puede participar de ontología alguna. En este sentido, la escenografía de la inteligibilidad platónica de los cuerpos depende de la exclusión de las mujeres y demás seres que, según el pensamiento de Platón, no poseen razonamiento. Sin embargo, hay una contradicción en este planteamiento, ya que de alguna manera Platón nombra y afirma algo que él considera no puede ser representado de ninguna manera, al entender la Chora como un lugar de inscripción inicial. Al nombrar lo que no puede ser nombrado, bajo un razonamiento bastardo -figura catacrésica- transgrede el receptáculo que él mismo considera como ininteligible. En últimas, lo que pretende Irigaray es reintroducir lo excluido, a partir de una exageración o un exceso de lo metonímico. Es decir que, es en la variedad de representaciones oníricas y espurias en las que Irigaray intenta burlarse del discurso falogocentrico, "este exceso metonímico de toda imitación, en realidad de toda sustitución metafórica, es lo que considera que quiebra la repetición sin fisuras de la norma falogocéntrica" (Butler, 2002, p. 85).

Para Butler, en primer lugar, la noción de la materia en la reflexión de Irigaray se reduce a un concepto metafísico que está al servicio del falogocentrismo; en segundo lugar, se limita a una figura espuria o catacrésica que da lugar a la imitación, la cual, a partir de la sustitución metafórica, modifica y hace frente a la relación asimétrica que pervive entre mujeres y hombres. En ese sentido, esta perspectiva no ve la materialidad del sexo, sino el sexo en la materialidad, es decir que considera la materialidad únicamente como una base para comprender la jerarquía sexual, perdiendo de vista que todo proceso de significación genera exclusión.

Butler se pregunta si lo femenino es lo único que queda excluido, pues Irigaray en su análisis, no hace referencia a otros seres que también se consideran externos a la normalización, y que no ocupan un rol dentro de las jerarquías de la matriz generizada. Una de las conclusiones a las que llega Butler con su búsqueda genealógica, es que la noción de materia lleva un lastre debido a que envuelve una violencia interna, pues solo considera que los cuerpos válidos son establecidos, como tal, por la exclusión de otros cuerpos posibles; por esta razón, esta búsqueda tiene como fin comprender y cuestionar los intereses que afirman tales posturas metafísicas, para no repetir y caer de nuevo en la misma lógica de la exclusión, como le sucedió a Irigaray y a la invocación psicoanalítica como se verá a continuación.

\section{Límites de las categorías del psicoanálisis, más allá de lo simbólico y lo imaginario}

El análisis de Butler en Cuerpos que importan (2002), no solo se concentra en develar el papel de la lógica de exclusión formulada desde la matriz heterosexista, sino que también se preocupa por ahondar la revisión estructural presentada por el psicoanálisis en la versión freudiana y lacaniana, para la cual el falo se constituye como organizador simbólico del yo. En la tarea por enriquecer el análisis, Butler se concentra principalmente en la Introducción al 
narcicismo y otros ensayos (2005) y El yo y el ello (2000) de Freud, y los textos: El estadio del espejo como formador de la función del yo tal y como se nos revela en la experiencia psicoanalítica (2002), así como La significación del falo (2013), en la obra de Lacan.

Butler afirma que el objetivo de Freud en la Introducción al narcicismo y otros ensayos, es explicar la teoría de la libido a través de las experiencias del dolor y la enfermedad, ya que las dolencias orgánicas tienen la capacidad de reiteración de la libido sobre los objetos de amor y sobre sí mismos. En este sentido, la aparición del dolor físico (la hipocondría en textos posteriores de Freud hace evidente una parte del cuerpo localizada que se confirma conscientemente. Esta idea de la aparición del cuerpo se presenta con mayor claridad en El yo y el ello, en el que Freud asume el dolor corporal como instancia previa del autoconocimiento del cuerpo (Butler, 2002), y al mismo tiempo, como relación determinante con la imagen externa de este para la formación del yo.

Para Freud, la hipocondría como localización del dolor queda sustituida por los órganos genitales en estado de excitación, hecho que configura a los ojos de Butler una relación directa entre el cuerpo, el dolor y lo erógeno para fabricar una epistemología específica y limitada del cuerpo, al mismo tiempo que establece la formación del yo. El problema de esta interpretación sobresale cuando el órgano genital masculino se ubica como prototipo de significación, y al unísono se convierte en el órgano privilegiado para la sustitución de otras zonas erógenas del cuerpo. Es en este sentido, que las tesis psicoanalíticas freudianas han recibido profundas críticas desde la corriente del lesbofeminismo9, las cuales son retomadas por Butler en tanto que, ella considera que la asignación de un ideal de representación del falo como origen y prototipo (como ideal simbólico y, al mismo tiempo, anatómico para formar el imaginario) resulta delimitante para la formación y afirmación del cuerpo en el mundo social.

El falo se idealiza, entonces, como significante privilegiado al representar: a) el efecto de un conjunto de sustituciones, b) el origen que permite la existencia de esas sustituciones y por tanto confiere erogeneidad y significación al cuerpo ${ }^{10}$ y c) la figura de asimilación epistemológica del cuerpo. Estas cualidades le permiten a Butler afirmar la indisoluble relación entre el pene y el falo en la teoría freudiana, desde la cual se construye, a este último, como principio de transferibilidad, expropiabilidad y plasticidad.

9 El lesbofeminismo es quizá el grupo de teorías feministas que más ha enfatizado en la idea de la heterosexualidad como materialidad forjadora de subjetividades. Es en este sentido, que la crítica general sobre el psicoanálisis, planteada por Butler a lo largo de Cuerpos que importan (2002), sirve para ampliar la crítica no solo a la subjetividad como delimitación política, tal como la reconstruye Monique Wittig (2006) en su ensayo sobre El pensamiento heterosexual, sino como delimitación y posibilidad de aparecimiento de los cuerpos.

10 La idea de la asimilación del cuerpo como presupuesto es insalvable en esta perspectiva, porque la idea del cuerpo y la aparición del cuerpo fenoménico son generados simultáneamente, es decir que, "existe una indisolubilidad entre una parte corporal y la partición fantasmática que la lleva a la experiencia psíquica" (Butler, 2002, p. 98). 
Si el falo es necesariamente una propiedad transferible, se rompe con la distinción de tener el falo o ser el falo ${ }^{11}$, y esto permitiría poner en cuestión la matriz heterosexual que asume el "tener" como una propiedad atribuible a aquellos seres que se identifican con el ideal masculinista heteronormativo (Butler, 2002).

La cuestión de la transferibilidad del falo pone en evidencia que la formación de identificación y atribución no pueden operar bajo la distinción entre el tener y el ser como términos excluyentes y contradictorios. Para Butler, el sistema de transmisión fálica no puede negar la posibilidad de la plasticidad de éste, y por tanto, pensar en que el falo lesbiano es una representación espectral del ideal masculino, forzaría a reducir el papel transferible y significante del mismo, solamente bajo un ideal masculinista.

De alguna forma, el discurso freudiano que relaciona el dolor con lo erógeno para construir un yo, y que al mismo tiempo utiliza esa sustitución como herramienta para demarcar los límites prohibitivos del amor, sostiene una relación directa entre la culpa y lo patológico. El discurso del dolor y la culpa, unido a la prohibición, delinea por tanto el pensamiento freudiano de la tacha sobre la homosexualidad, ejercida por la auto-normación del ideal del $y o^{12}$. Esta estructura delimitativa de la norma heterosexual, reiteraría el carácter fantasmático con el cual, por ejemplo, el falo lesbiano se cubre al interior del sistema freudiano, pues, en cuanto "las prohibiciones que instituyen el género operen inundando el cuerpo con un dolor que culmina en la proyección de una superficie, esto es, una morfología sexuada que es a la vez una fantasía compensatoria y una máscara fetichista" (Butler, 2002, p. 106). La restricción morfológica del mismo contendrá un sello de estas delimitaciones y expresará la melancolía de lo perdido, al entrar en la matriz diferenciadora; de operar en el sentido contrario, el cuerpo será tildado como un cuerpo enfermo.

De esta situación paradigmática entre el dolor y la culpa, Butler reconsidera el papel configurador de lo simbólico más allá de un episodio vinculante restrictivo. Tomando en consideración que persiste en el discurso freudiano una relación entre lo psíquico y lo físico, "la circulación y validación del esquema imaginario", es efectivamente el cuerpo. Es decir que, no habría una situación liminar y unívoca en la que la psique prefabrique los cuerpos, o una materialización unívoca que determine la figuración psíquica de los mismos. Las dos esferas se enmarcan en una demanda en y por el lenguaje, que implican la materialización como "un sitio de actuaciones y pasiones de diversa índole" (Butler, 2002, p.109), en la cual y sobre la cual, la psique tiene su sitio de operabilidad.

11 La distinción entre ser o tener el falo tiene dos interpretaciones diferentes en la tradición freudiana y lacaniana. Mientras que la diferencia entre ser y tener el falo implica para Freud circunscribirse al orden de la falta y la castración de la madre en la salida del cuadro edípico; en la obra de Lacan, la diferencia entre ser y tener el falo está circunscrita al orden simbólico, y no al mito de la castración. Para profundizar sobre el tema ver La significación del falo de Lacan (2013).

12 Para una ampliación de las diferencias entre el ideal del yo como construcción neutral entre el yo y la ley cultural y el yo ideal como una autoafirmación del yo, consultar el trabajo de Freud sobre el narcicismo (Freud, 2012). 
Esta carga relacional implica comprender que los discursos que denotan la materialidad del cuerpo, no se trazan sobre referentes constituidos y estables, sino que se construyen sobre aquello no resuelto permanentemente, ni el género como constante, ni la diferencia sexual como determinada. De allí que cobre gran importancia el ejercicio del lenguaje, en cuanto signo y eficacia significativa, pues este se presenta como una materialidad que involucra la cuestión de la emergencia, incluso en el acto mismo de la significación;

[...] en este sentido, pues, el lenguaje y la materialidad no se oponen, porque el lenguaje es y se refiere a aquello que es material, y lo que es material nunca escapa del todo al proceso por el cual se le confiere significación. (Butler, 2002, p. 110)

En tanto el lenguaje y la materialidad no están exactamente identificados, ni extremamente diferenciados, es preciso hacer evidente cómo la morphe $e^{13}$ limita la forma de aparecimiento del cuerpo mediante la cual queda marcado el carácter distintivo de lo material. Este hecho se hace latente en la precisión de Kristeva, según la cual, el lenguaje se convierte en acto primario de condensación y desplazamiento (Butler, 2002); en este sentido, el lenguaje opera como desplazamiento de ese otro (cuerpo) que se pretende capturar, y que, en la captura expresada por los significantes, aparece fantasmáticamente. La materialidad entonces, en cierto sentido, se adquiere y constituye por la morfología; como lo Real en Lacan, se resiste a la simbolización y al mismo tiempo la impone. Esta ambivalencia constante, se traduce en el proceso de iteración que se convierte en ley, en estructura que posibilita el aparecimiento de los cuerpos en sentido binario.

La morfología corporal y lingüística, en este sentido, se unen y resisten, entrelazándose en una constante tensión que terminará en la formación de la frontera corporal. Sobre esto, Butler hace referencia a El estadio del espejo de Lacan, en el cual se advierte la operación de un tercer elemento para la aparición de la morphe, que resuelve la tensión entre el lenguaje y la materia, desde el lugar de lo imaginario, como capacidad de proyección de aquella. Para dar cuenta de esta postura, la autora analiza los efectos que deja la perspectiva narcisista de Freud en las ideas de Lacan, específicamente en la constitución del yo corporal y la diferenciación sexual, a través del juego de lo imaginario y lo simbólico.

Es claro que para Butler una estructura dominante continúa siendo tal, en la medida en que persiste y se repite en la cultura; no obstante, afirma que "[...] como cosa reiterable queda abierta a la variación y a la plasticidad" (Butler, 2002, p. 140). Esto quiere decir que, la repetición o reiteración para Butler no hace referencia a una simple imitación, sino a una suerte de traducción que abre la posibilidad de modificar la norma del género y el sexo, en la medida en que el acto reiterativo envuelve una inestabilidad o

13 La ampliación del sentido de la Morphe en Kristeva implica que la materialidad de los cuerpos está trazada por la materialidad del lenguaje, que contiene "un doble juego del aislamiento y de la atracción, es decir una irreductibilidad al mismo tiempo que una síntesis" (Kristeva, 1981, p. 22). 
estadio de la contingencia. El "falo lesbiano" y sus alcances son el resultado de esta iteración, porque logra invertir la lógica que establece el intercambio sexual impuesto por la estructura heteronormativa, respecto a "ser" o "tener" el falo. El "falo lesbiano" permite una transferencia de sentido y con esto le hace frente al poder que tiene el falo como significante privilegiado en la estructura heteronormativa.

En este marco general, la obra de Lacan cobra importancia pues para él, a partir de las reglas del parentesco y la diferenciación sexual, un individuo se constituye como sujeto en tanto que asume una posición dentro de lo simbólico. En el primer ensayo, El estadio del espejo (2002), el autor considera que el tema de la formación corporal tiene que ver con una representación imaginaria que le da coherencia al cuerpo desintegrado; mientras que, en un segundo momento, afirma que la comprensión corporal como totalidad, solo puede sostenerse a partir de una integridad fantasmática de la diferenciación sexual, que hace que el individuo se vea obligado a posicionarse en lo simbólico. Por tanto, el falo llega a tener el carácter de significante privilegiado y ordenador de lo que puede ser significado, en el momento en el que se configura la idealización del cuerpo en los dos niveles mencionados.

Según Lacan, la relación imaginaria y la relación simbólica se expresan en dos narrativas diferentes, aun cuando se identifican porque apelan a una extrapolación o sinécdoque. En el "estadio del espejo" (nivel imaginario) comienza la relación del individuo con una proyección psíquica, en la que el lenguaje aún no actúa con su poder diferenciador. En este nivel, se proyecta la forma, la imagen especular del cuerpo a través del cuerpo del otro, y al mismo tiempo, se establece la frontera entre "lo exterior" y "lo interior" como criterio de control e identificación.

Por su parte, la narración simbólica da cuenta del modo como el cuerpo responde ante la Ley, por la necesidad de encontrar una posición clara como sujeto bajo la determinación de la diferencia sexual. El lugar estructural del falo es un topos que determina las relaciones a través de la lógica de no contradicción, de la exclusión mutua en el momento de delimitar quién "tiene" y quién "es" el falo. Este análisis, afirma Butler, sugiere un presupuesto que la perspectiva lacaniana no justifica y que estaría inmune a cualquier genealogía. Pensar que el cuerpo está dividido en partes, implica suponer una idea inicial de integridad y coherencia, es decir, una condición previa de sentido. En últimas, se considera que el falo es una representación preliminar. $\mathrm{Al}$ respecto afirma Butler que "[...] el falo gobierna la descripción de su propia génesis y, en consecuencia, se protege de una genealogía que podría conferirle un carácter derivativo o proyectado" (Butler, 2002, p. 129).

Es preciso advertir, que el "falo" en Lacan se define negativamente ${ }^{14}$, es decir, a través de los atributos que no le pertenecen: no es un objeto, no es

14 Para Butler, cuando Lacan sugiere gradaciones de la significación del falo, negando su relación con una parte anatómica (el pene), cae en la distinción de lo que es el falo, solamente a través de la negación de la existencia del pene, esto implica que el falo se convierta en un significante, que busca separarse de la parte del cuerpo que representa. 
un efecto de lo imaginario, no es una categoría parcial, no es una fantasía, y mucho menos un órgano, simplemente es un significante o una idealización de la anatomía. Aquí Lacan sugiere que no hay una relación directa entre el objeto de simbolización y el símbolo que actúa en ese procedimiento; esto es, no hay una relación ontológica entre el símbolo y lo simbolizado. En este sentido, el falo, que es el significante privilegiado y que, al mismo tiempo, no se identifica únicamente con un órgano del cuerpo específico, es decir, con el pene, supera la paradigmática relación entre el ser y el tener, propia de la teoría de la castración freudiana, e impide que el falo caiga en una catacresis que invoque una proliferación de significados. El falo en esta perspectiva funciona como un lugar de control que no tiene significado y que, por lo tanto, está en la capacidad de otorgarlo.

La posibilidad del "falo lesbiano" aparece cuando lo simbólico implica un desplazamiento, al adquirir la capacidad de significar desde otra parte del cuerpo diferente al pene. Esto quiere decir que, el sentido del significante puede ser transferible. Si una lesbiana tiene el "falo" invierte o trasgrede el sentido tradicional. De allí que, el falo, al revestir un carácter ambivalente, podría salirse del régimen heterosexista en el que se ve configurado, pues, aunque el deseo no se libra de las demandas normativas,

se puede decir que el falo lesbiano interviene como una consecuencia inesperada del esquema lacaniano, un significante aparentemente contradictorio que, a través de una mimesis crítica, pone en tela de juicio el poder ostensible originador y controlador del falo lacaniano o más precisamente, el hecho de que se instale como el significante privilegiado del poder simbólico. (Butler, 2002, p. 117)

Esta interpretación de la tradición psicoanalítica en las versiones freudiana y lacaniana contribuye a cuestionar el papel dual entre "ser" y "tener" el falo, así como la relación de estos con el cuerpo masculino (el pene). La desarticulación de las estructuras de significación y de los roles de poder, usados reiterativamente a través de los imaginarios sociales construidos y solidificados por el acto de la repetición que establecen la diferencia sexual, quedan desmantelados de su aparente investidura de naturalidad cuando Butler anuncia que el poder de la repetición tiene la capacidad de establecer materialidades específicas de los cuerpos. El falo, al ser un significante privilegiado (que significa siempre), está en proceso de ser significado o resignificado.

En este sentido, no es el momento u origen incipiente de una cadena significante, como diría Lacan, sino que es una parte de una reiterada práctica significante, que queda abierta por lo tanto, a la reinterpretación: capaz de significar en modos y lugares que exceden su lugar estructural apropiado en lo simbólico lacaniano y de cuestionar la necesidad de ese lugar. (Butler, 2002, p. 139)

En conclusión, para Butler la postura de Lacan es problemática, porque: (I) considera que el único esquema morfológico válido para la aparición corporal está marcado por lo masculino y (II) es sesgado pensar que la 
"significación del falo" va unida a la significación corporal. De lo anterior, resulta problemático que el único establecimiento epistemológico tenga un carácter androcéntrico fálico, por lo cual, la dimensión de la lectura butleriana sobre la materialidad del cuerpo y su capacidad de aparecimiento cuestiona las dimensiones del género y la diferencia sexual; al tiempo que, sostiene que la noción de falo lesbiano abre paso a indagaciones que tienen como objetivo: "reconsiderar las relaciones tácitamente políticas que se instalan y persisten entre las partes del cuerpo y la totalidad, entre la anatomía y lo imaginario, entre la corporalidad y la psique" (Butler, 2002, p. 117).

\section{Aportes del análisis butleriano al campo jurídico}

Las principales apuestas teóricas que dan curso a un programa teórico práctico, presente ya desde el Género en disputa en el trabajo de Butler, son retomadas en esta versión con un profundo sentido de la construcción performativa a la luz del análisis de la materialidad de los cuerpos. La crítica establecida, en la primera sección de este artículo, sobre el constructivismo feminista y el enfrentamiento a la tradición de la filosofía y el psicoanálisis como constructoras de matrices de regulación permiten considerar desde una perspectiva, si se quiere postfeminista, las implicaciones de los conceptos de género y diferenciación sexual para la aparición de los sujetos en el plano social.

El escenario político que se lucha entre las prácticas puramente sociales y las disputas por la transformación de los paradigmas institucionales, se concentran en mostrar que gran parte del desarrollo de las políticas de la identidad producidas con el origen de las luchas de las mujeres y las comunidades afro entre las décadas de 1970 y 1980 en Norteamérica, han construido barreras que limitan la comprensión de identidades móviles y des-sujetadas, como afirma Butler. En ese sentido, reflexionar sobre la identificación, el papel del deseo y la apuesta de desarticulación de la ley, a través de su reinterpretación, permiten imaginar nuevas alternativas para el campo jurídico.

El principal aporte de la cuestión del género y la diferencia sexual en la obra de Butler consiste en desarticular el lugar naturalizado de esta última, al tiempo que demuestra la existencia del poder de la norma, no solamente como un acto constituyente, ubicado en un tiempo y espacio determinado, sino que hace evidente que la regulación de la diferencia sexual solamente cobra el sentido normativo (la fuerza de ley) si se entiende como un proceso de iteración. Este implica, en primer lugar, que el sujeto se reconozca en esas normas y las considere como una condición de existencia y, en segundo lugar, que esas normas se establezcan a través de un acto ritualizado; al respecto afirma Butler que: "Sujeto al género, pero subjetivado por el género, el 'yo' no está ni antes ni después del proceso de esta generización, sino que sólo emerge dentro (y como matriz de) las relaciones de género mismas" (Butler, 2002, p. 25).

Esta matriz del poder, analizada por Butler a través de la genealogía de la inteligibilidad de la materialización corporal, evidencia una lógica de la exclusión en el que la primacía normalizadora de la heterosexualidad 
responde a un ejercicio estructural de excepción; en la cual, paradójicamente, los cuerpos abyectos son constitutivos como condición y límite de la diferencia sexual. Las posibilidades que tiene un sujeto, entonces, para configurarse como tal, se enmarcan en el binario femenino-masculino; sin embargo, para que esta lógica binaria se establezca y perviva, se requiere del abismo fantasmático de lo abyecto ${ }^{15}$.

El aporte de Butler, en este sentido, se dirige a repensar cómo aparecen los cuerpos más allá de las categorías del género establecidas en el código binario hombre-mujer, pues enuncia que el poder de las teorías identitarias del género, están en la base de la formación de las subjetividades. Este hecho implica la delimitación para la exclusión o, en el mejor de los casos, la incorporación violenta de los cuerpos que se manifiestan de formas diversas y que, para hacer parte del entramado social, deben acatar las normas de generización, que el discurso jurídico procura mantener. La excepcionalidad corporal -los cuerpos abyectos y excluidos de la matriz de generización-, en otras palabras, las identidades temidas son una posibilidad práctica para poner en cuestión los esquemas imaginarios morfológicos y superar la lógica de la exclusión. Pues, en primer lugar, las estructuras normativas son inestables, lo que implica que el yo corporal es un objeto vacilante, porque la identificación es un juego que responde a una negociación insistentemente. “[...] Lo que opera bajo el signo de lo simbólico no puede ser otra cosa que precisamente ese conjunto de efectos imaginarios que han llegado a ser naturalizados y reificados como la ley de significación" (Butler, 2002, p. 126). En segundo lugar, la única manera de quitarle privilegio al falo como significante privilegiado, dentro de la lógica heteronormativa, es a través de la fuerza de la resignificación o reinterpretación, ya que esta no es imitación, sino que permite una posibilidad distinta. En este sentido, es pertinente afirmar que Butler no apunta a una nueva ontología ${ }^{16}$, sino a las posibilidades que quedan abiertas en la reiteración de esa estructura dominante y hetero-reglada.

De las restricciones y los límites simbólicos, se crea la posibilidad de desafiar a la ley reguladora. Esto implica que la restricción opere como un requisito de la performatividad, debido a que la iteración establece conductas como habituales, a partir de la fuerza de la prohibición y el tabú. De allí que, la formación de la identidad en la estructura heteronormativa se establece como restricción constitutiva, a través de la castración y el castigo, dejando fuera de sus términos (y por esto constituyéndolo) la homosexualidad abyecta. Las restricciones que se fijan en el binario masculino-femenino, se constituyen a través del temor de ocupar alguna de estas formas abyectas y, por tanto, del miedo a perder la condición de sujeto.

15 Es preciso advertir que, la aversión y la exclusión de los cuerpos que no importan son la consecuencia de la reiteración de la norma.

16 Al respecto, afirma Butler lo siguiente en una entrevista del 2012: "Me preocupaba que, al centrarnos exclusivamen-te en las políticas de identidad, estuviéramos haciendo proliferar categorías normativas de identidad que harían la vida menos habitable para los gender queer y que la dificultarían también para aquellas personas que tenían una noción de sí mismas como habitando fuera de las categorías establecidas" (Soley-Beltran y Sabsay, 2012, p. 225). 
Esta compleja formación de la identidad pone en cuestión los límites de la estabilidad de las líneas del parentesco y la movilidad del deseo más allá de las estructuras prefijadas. Al estar en constante negociación entre lo prohibido y lo desviado, la identificación se construye como "una escenificación fantasmática” (Butler, 2002, p. 159), atada a una lógica volátil de lo iterable. Esto implica que la interpretación de la diferencia sexual de Butler se aleje sustancialmente de propuestas alternativas de inclusión política, a partir de la ampliación y reconocimiento jurídico a otros géneros posibles, pues este hecho solo produciría nuevas formas de exclusión (Butler, 2006).

Es por esto que, Butler propone una afirmación política más allá del repudio, en la cual, no solamente debe establecerse una oposición ante la ley de la diferencia sexual, sino que, desde el acto de la cita, entendida como una reiteración de la norma, se puede resignificar el carácter anticonvencional de lo simbólico. Esto quiere decir que, no es necesario establecer una ampliación de la ley, en la cual se reconozcan las diferencias de estos cuerpos inhumanos o abyectos; sino que, desde la capacidad de citación de la norma (iteración), se pueden proliferar consecuencias inesperadas de lo simbólico mismo, que evidenciarían el mapa dinámico en el que opera la identidad ${ }^{17}$. Por lo tanto, lo importante no es establecer una identificación nueva que sea incorporada a la estructura simbólicojurídica, es decir, una produción ontologica ampliada; sino, más bien, lo que se debería pensar es cómo al cuestionar y quebrar la ley se puede exceder y confundir la intención disciplinaria de esta, llevando paulatinamente a una deconstrucción del género, que se produzca desde el campo de la decisión judicial, como acción política.

Este hecho no excluye, como lo evidencia el estudio realizado por Michel Cruz Rodríguez (2012) en el artículo "Múltiples derechos, la misma desprotección: la eficacia simbólica de los derechos de las mujeres indígenas desplazadas en Colombia", que la tarea crítica frente al derecho no sea una vía de acción efectiva, en tanto que, el análisis discursivo que propone Butler, ayuda a comprender cómo en ciertas condiciones este es ineficaz. Tal como lo resalta el autor, a propósito de la desprotección que experimentan las mujeres indígenas desplazadas, aun cuando a su favor existen una serie de garantías legales tanto internacionales como locales, la aplicación del derecho se hace ineficaz por el discurso patriarcal con en el que, en algunas situaciones, se interpretan dichas garantías, las cuales continúan generando discriminación y opresión.

17 Sobre este punto, Butler hace un aporte interesante frente a las limitaciones de la identificación coherente y las posibilidades de usar la identidad estratégicamente, dentro del mapa dinámico del poder, en el cual se paralizan, se despliegan, se constituyen. 


\section{Referencias}

Beauvoir, S. (2005). El segundo sexo. Madrid: Ediciones Cátedra.

Burgos, E. (2008). Quécuenta como una vida. La pregunta por la libertad en Judith Butler. Madrid: Antonio Machado Libros.

Butler, J. (2002). Cuerpos que importan. Sobre los limites materiales y discursivos del "sexo". Trad. Alcira Bixio. Buenos Aires: Editorial Paidós.

Butler, J. (2006). Regulaciones de género. Revista de estudios de género. La ventana. 23, 7-35. Recuperado de http://www.lazoblanco.org/wp-content/ uploads/2013/08manual/bibliog/material_masculinidades_0113.pdf

Butler, J. (2007). El género en disputa. El feminismo y la subversión de la identidad. Trad. M. Antonia Muñoz. Barcelona: Editorial Paidós.

Butler, J. (2008). ¿Qué es la crítica? Un ensayo sobre la virtud de Foucault. En B. Buden, J. Butler, A. De Nicola, B. Holmes, J. Kastner, M. Lazzarato, ... M. Von Osten, Producción cultural y practicas instituyentes. Lineas de ruptura y crítica institucional (pp. 141-168). Madrid: Traficantes de sueños. Recuperado de https://www.traficantes.net/sites/default/files/pdfs/Produc ci\%C3\%B3n\%20cultural-TdSs.pdf

Cruz Rodríguez, M. (2012). Múltiples derechos, la misma desprotección: la eficacia simbólica de los derechos de las mujeres indígenas desplazadas en Colombia. Revista Estudios Socio-Jurídicos, 14(2), 289-326. Recuperado de https://revistas.urosario.edu.co/index.php/sociojuridicos/article/view $/ 2118$

Di Giorgi, L. (2013). Los afectos, las ideas y la formación de sujeto en Spinoza. (Tesis de Maestría). Universidad del Rosario.

Etimologías.dechile.net. (s.f.). Etimología de catacresis. Recuperado de http:// etimologias.dechile.net/?catacresis

Foucault, M. (2007). Historia de la sexualidad 1. Voluntad de saber (31.a ed.). Trad. Ulises Guiñazu México: Siglo Veintiuno Editores.

Foucault, M. (2009). Vigilar y castigar. Nacimiento de la prisión (2.a ed.). México: Siglo Veintiuno Editores.

Freud, S. (2000). El yo y el ello. Obras completas. Buenos Aires: Amorrortu Editores.

Freud, S. (2005). Introducción al narcicismo y otros ensayos. Trad. Luis López y Ramón Rey. Madrid: Alianza Editorial.

Freud, S. (2012). Introducción al narcisismo y otros ensayos. Trad. Luis López y Ramón Rey. Madrid: Alianza Editorial. 
Gatens, M. (1996). Imaginary bodies. Ethics, power, and corporeality. Londres: Routledge.

Irigaray, L. (2007). Espéculo de otra mujer. Trad. Raúl Sánchez. Madrid: Akal.

Irigaray, L. (2009). Ese sexo que no es uno. Madrid. Akal.

Kristeva, J. (1981). Semiótica II (2.a ed.). Madrid: Editorial Fundamentos.

Lacan, J. (2002). El estadio del espejo como formador de la función del yo [Je] tal como se nos revela en la experiencia psicoanálitica. En Escritos I (pp. 86-93). Buenos Aires: Siglo Veintiuno Editores.

Lacan, J. (2013). La significación del falo. En Escritos II (pp. 653-662). Madrid: Editorial Biblioteca Nueva.

Martinez, A. (2012). El falo descentrado. Judith Butler, Donna Haraway y Beatriz Preciado: perspectivas conceptuales en torno al cuerpo. IV Congreso Internacional de Investigación y Práctica Profesional en Psicología XIX Jornadas de Investigación, viII Encuentro de Investigadores en Psicología del Mercosur, Universidad de Buenos Aires, Buenos Aires. Recuperado de https://www.aacademica.org/000-072/48

Sabsay, L. (2010). ¿En los umbrales del género? Beauvoir, Butler y el feminismo ilustrado. Feminismo/s, 15, 119-135. Doi: http://dx.doi.org/10.14198/ fem.2010.15.07

Scott, J. (1996). El genero una categoría útil para el análisis histórico. En M. Lamas (comp.), El género: la construcción cultural de la diferencia sexual (pp. 265-302). México: Universidad Nacional Autónoma de México - Miguel Ángel Porrúa Editor.

Soley-Beltran, P. y Sabsay, L. (eds.). (2012). Judith Butler en disputa. Lecturas sobre la performatividad. Madrid: Editorial Egales.

Wittig, M. (2006). El pensamiento heterosexual y otros ensayos. Trad. Javier Sáez y Paco Vidarte. Barcelona: Editorial Egales. 